\title{
Researching the Application of CFG Pile Treatment in Soft Foundation of Expressway
}

\author{
Zhang Lijie ${ }^{1, a}$, Qing Wei, ${ }^{2, b}$, Sun Shiwei ${ }^{3}$,Li Haibin ${ }^{4}$ \\ 1Department of Architecture and Civil Engineering ,Xi'an University of Science and Technology, \\ Xi'an, 710054, China \\ ${ }^{2}$ School of Materials Science and Engineering, Chang'an University, Xi'an 710064, China; \\ ${ }^{3}$ School of Materials Science and Engineering, Chang'an University, Xi'an 710064, China; \\ ${ }^{4}$ Department of Architecture and Civil Engineering ,Xi'an University of Science and Technology, \\ Xi'an, 710054, China; \\ a782532634@qq.com, ${ }^{\mathrm{b}}$ lihaibin1212@126.com
}

Keywords: CFG Pile, soft soil foundation, expressway.

\begin{abstract}
CFG (Cement Fly-ash Gravel) pile is consisted with macadam, gravel, sand, fly ash mixed with cement and water. In sand, silt, clay and muddy soil and miscellaneous fill foundation, there have been many applications of CFG technology. The attentions and matters of CFG processing are analyzed in this paper.
\end{abstract}

\section{Introduction}

CFG Pile is the abbreviation of Cement Fly-ash Gravel pile. CFG pile is consisted with macadam, gravel, sand, fly ash mixed with cement and water, and the typical characteristic is its variable strength. In different cement content and mix proportion condition, the strength grade of CFG is between C15 to C25, and also is between rigid pile and flexible pile. Because CFG pile and soil form composite foundation by cushion, it can be calculated and designed by the principle and characteristics of composite foundation. The reinforcement of CFG pile need not be calculated in engineering. In addition, some industrial waste such as fly ash, silica fume, bottom ash and stone chips can be used as admixture to reduce the cost. Fig. 1 shows soft foundation treated by CFG piles.

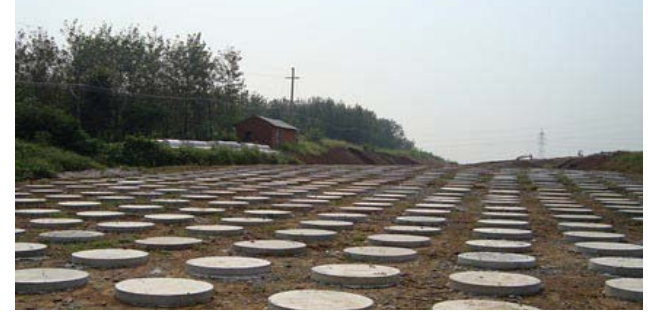

Fig. 1. Soft Foundation Treated by CFG Piles

\section{Working Principle of CFG Pile}

CFG pile is a kind of high bond strength pile that is consisted with macadam, gravel, sand, fly ash and mix up cement and water, and form composite foundation with cushion and soil between piles together. This kind of composite foundation is often used in foundation treatment of high-rise building, super high-rise buildings and expressway.

The basic working principle of CFG pile can be explained simply as composite foundation, which CFG pile works together with soil between piles by the cushion and connects the base when

CFG pile end on soil layer or hard soil layer. Moreover, compared with soil between piles, the strength and modulus of CFG pile is bigger, and stress on the top of CFG pile is bigger than stress on the surface of soil between piles under load. On this condition, CFG pile can transfer load to deeper 
soil layer to reduce load borne by soil between piles. Therefore, because of the effect of CFG pile, the bearing capacity of foundation increases and the deformation decreases.

The certain thickness of cushion usually composed of particle materials is set among CFG pile, foundation and soil. The load-bearing characteristic is similar between foundation and pile foundation without cushion, and composite foundation can not be formed because of the low bearing capacity of soil between piles. For setting cushion under base, the bearing capacity of composite foundation is not only provided by the settlement of pile, but also by CFG pile and soil working together. By laying certain thickness and gradation of stone and gravel or coarse sand and medium sand, the cushion of thickness is between 10 to $30 \mathrm{~cm}$, it can be formed in this common construction way. The cushion can spread load on base to soil between piles to make CFG pile and soil work together.

In addition, there is no reinforcement in CFG pile, and the fly ash of industrial waste is used as admixture, reducing project cost greatly.

\section{Material Requirements of CFG Pile}

(1) Concrete and admixtures (retarder and fly ash) should meet the requirements of corresponding standard, and the amount of mixing should be determined by laboratory tests according to the requirements of construction.

(2) The material composition of CFG pile must be strictly in accordance with mix proportion.

(3) For the long helical drilling and tube pumping bored pile, the slump of concrete should be controlled in $160 \sim 200 \mathrm{~mm}$. For the vibration sinking bored pile, the slump of concrete should be controlled in $30 \sim 50 \mathrm{~mm}$. After pile is completed, the thickness of laitance on pile top should be less than or equal to $200 \mathrm{~mm}$.

(4) For the long helical drilling and tube pumping bored pile, the time of lifting drill pipe should be paid attention when drilling to design depth. The speed of lifting drill pipe should match the quantity of pumping mixture, and the mixture pumping can not stop when drilling to saturated silt layer or saturated sand layer. The speed of lifting drill pipe should be even after construction is completed, and it should be slow down when drilling to mud layer or muddy soil layer.

\section{Construction of CFG Pile}

Fig. 2 shows the construction process of CFG pile, but for different soft foundation, it should adopt different construction technology.

(1)For silt, cohesive soil, medium dense sand, and plain fill foundation, etc. above ground water level, it should adopt the construction technology of long helical drilling bored pile;

(2) For silt, cohesive soil, sand and the foundation strictly controlled of noise or mud pollution, it should adopt the construction technology of long helical drilling and tube pumping bored pile;

(3) For the silt, cohesive soil and plain fill foundation, it should adopt the construction technology of vibration sinking bored pile that is often used in soft foundation treatment while on expressway now.

The construction technology of vibration sinking bored pile is that vibrator is installed at the upper end of pile pipe, and tip is installed at the lower end of pile pipe, then pile hole is formed by sinking pile pipe into design depth under the action of vibrator, then reinforcement cage is hoisted into pile pipe, finally pile is completed by filling pile pipe with concrete. Fig. 3 shows the construction of CFG pile.

\begin{tabular}{|c|c|c|c|c|c|}
\hline Leveling Site & $\rightarrow \quad$ Locating Pile & $\rightarrow$ & \begin{tabular}{|l} 
Pile Machine at \\
Position \\
\end{tabular} & $\rightarrow$ & $\begin{array}{l}\text { Pile Pipe and Drill at } \\
\text { Position }\end{array}$ \\
\hline$\downarrow$ & & & & & \\
\hline $\begin{array}{l}\text { Checking Concrete } \\
\text { Height in Pipe }\end{array}$ & $\leftarrow \begin{array}{l}\text { Pulling out Pile } \\
\text { Pipe or Lifting } \\
\text { Drill }\end{array}$ & $\leftarrow$ & $\begin{array}{l}\text { Preparing and } \\
\text { Checking Concrete }\end{array}$ & $\leftarrow$ & \begin{tabular}{|l} 
Sinking Pile Pipe or \\
Drilling to Design \\
Depth
\end{tabular} \\
\hline
\end{tabular}




$\stackrel{\downarrow}{\text { Filling Concrete }} \rightarrow$ Leveling Pile Top $\rightarrow$ Moving Pile Machine to Next CFG Pile Position

Fig. 2. Construction Process of CFG Pile

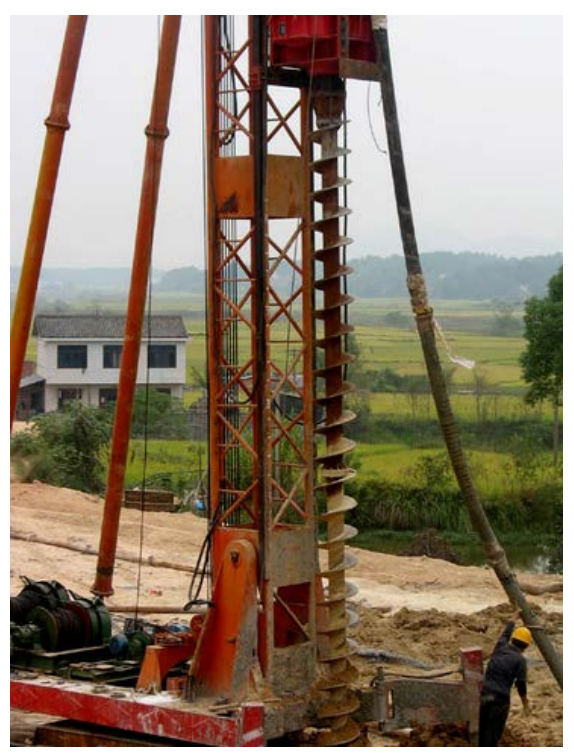

Fig. 3. Construction of CFG Pile

\section{Construction Notices}

(1)Site testing should be accorded to the requirements of design. The position of piles is from center to edge of road at intervals, and the time of interval between new and old piles are not less than 7 days.

(2) The drill pipe should be adjusted to vertical compared with ground before drilling, and the deviation is not more than $1 \%$.

(3) Because drill pipe can be sunk into design depth by the dead weight of pile machine, it is not better to use motor. When mixture fill up drill pipe, drill pipe can be lifted after vibrating $5 \sim 10$ seconds in situ. The speed of lifting drill pipe should be controlled strictly at $0.6 \sim 0.8 \mathrm{~m} / \mathrm{min}$. After lifting each $0.5 \sim 1.0 \mathrm{~m}$, drill pipe should be vibrated $5 \sim 10$ seconds in situ. The operation is repeated until drill pipe is pulled out.

(4) The filling coefficient of mixture should be greater than 1.15.

(5) The construction sequence of CFG pile should be adjusted to avoid pile machine rolling pile head.

(6) The foundation pit should be digged by human work after the detection of CFG pile is completed.

(7) The height requirement of CFG pile should be determined before chiselling off pile head. At first, pile head is broken by 2 or 4 steel drill robs placed symmetrically at same angle on same level, then pile head is chiselled off by steel drill robs and hand hammers from edge to center of pile.

(8) The process of driving pile should be known well when the condition of foundation is complex, and the CFG pile should penetrate mud layer into bearing layer not less than $0.6 \mathrm{~m}$.

\section{Application Example}

There is an arterial expressway construction project that the route length is about $13.05 \mathrm{~km}$, and the expressway is bidirectional 6 lanes, and the auxiliary road is bidirectional 4 lanes, and the base is $4 \%$ cement stabilized gravel subbase $+5 \%$ cement stabilized graded macadam base, and the pavement is 
cement concrete pavement of $25 \mathrm{~cm}$. CFG piles is used to treat an approach road of bridge for meeting requirement that the post-construction settlement is less than $10 \mathrm{~cm}$.

Final treatment: the diameter of CFG pile is $40 \mathrm{~cm}$, and the plane distribution of CFG pile is equilateral triangle based on calculating. CFG pile should penetrate soft soil layer into bearing layer more than $60 \mathrm{~cm}$, and the length of CFG pile is not more than $24 \mathrm{~m}$. The cement is ordinary Portland cement, and the macadam diameter is $20 \sim 50 \mathrm{~mm}$, and the gravel diameter is $2.0 \sim 10 \mathrm{~mm}$, and the fly ash is level III or above level III.

\section{Conclusion}

Soft foundation treatment is one of important problems in expressway engineering construction. CFG pile has advantages of reasonable economy, reliable technology, less investment, convenient transport and friendly environment, and has been widely used in domestic technology development and engineering applications. In addition, compared with other foundation treatment technology, CFG pile can save cost for $1 / 2 \sim 2 / 3$, and it has considerable economic benefit.

\section{References}

[1] Cui Shengdong, Application of CFG Pile in Soft Foundation Disposal of Expressway[J], Transport Standardization, 2009,198 (6) : 114-116.

[2] Yu Chunfang, Characteristics of Soft Soil Foundation and Treatment Methods [J], Transport Standardization, 2013,7,(14):16-18.

[3] Chen W F. Limit analysis and soil plasticity. New York: Elsevier Scientific Publishing Co., 1975.

[4] Duncan J M, Chang C Y. Nonlinear analysis of stress and strain in soils. Proc. ASCE, JSMFD 1970, 96(SM5), 1629 1633.

[5] R H G Parry, Mohr Circles. Stress Paths and Geotechnics. London: E \& FN SPOM, 1995. 